\title{
A construção do ser travesti
}

\author{
Antonia Nathalia Duarte Moraes ${ }^{1}$ \\ Geórgia Sibele Nogueira da Silva²
}

ISSN: $2358-0844$

ก. II, v. I mai. -out. 2019 р. $381-403$.

RESUMO: Este escrito pretende focar em uma das muitas reflexões sinalizadas ao término de uma dissertação que se propôs a compreender a vivência de pessoas travestis na busca por cuidados em saúde, na atenção primária. No âmbito deste artigo, ao fazermos um recorte da referida dissertação, nos debruçamos sobre a compreensão do que significa "ser travesti" para as nossas entrevistadas. Devido a imensa dificuldade em identificar na prática as categorias diferenciadoras das identidades de gênero, percebemos a necessidade de se discutir o significado do ser travesti para as próprias travestis. Utilizamos como instrumentos tecnometodológicos a entrevista em profundidade e oficina com uso de "cenas". Para análise interpretativa das narrativas recorremos à Hermenêutica-Dialética. A partir do diálogo com as narrativas chegamos aos seguintes resultados: o "ser travesti" como ser homossexual; ser feminina; não ser transexual; e aceitar-se. Diante das diversas formas que as entrevistadas se definiram enquanto travestis, vimos que não existe um processo específico de construção das suas identidades de gênero. Por fim, espera-se que a pesquisa possa contribuir com o campo do conhecimento acerca do saber-fazer na assistência às pessoas travestis, dentro e fora da academia.

PALAVRAS-CHAVE: travestis; transexualidade; homossexualidade; identidade de gênero; hermenêutica.

\begin{abstract}
This paper's aim is to focus on one of the many reflections signaled at the end of a dissertation that sought to understand the experience of transvestites in the search for health care, primary care. In the context of this article, when we perform a scoop selection on the dissertation, we concentrate on the understanding of what it means to be a transvestite for our interviewees. Due to the immense difficulty of identifying in practice the differentiating categories of gender identities, we acknowledge the need to discuss the meaning of being a transvestite for the transvestites themselves. We use as techno-methodological instruments the in-depth interview and workshop with use of "scenes". For the interpretive analysis of the narratives we refer to Hermeneutics-Dialectics. Through the dialogue with the narratives we achieved the following results: being "transvestite" as being homosexual; being female; not being transsexual; and self-acceptance. Given the different ways that the interviewees defined themselves as transvestites, we saw that there is no specific process for constructing their gender identities. Finally, it is hoped that the research can contribute to the field of knowledge regarding the know-how in assisting transvestites, both inside and outside the higher education sphere.
\end{abstract}

Keywords: travesties; transsexuality; homosexuality; gender identity; hermeneutics.

Resumen: Este escrito pretende enfocarse en una de las muchas reflexiones señaladas al término de una disertación que se propuso a comprender la vivencia de personas travestis en la búsqueda de cuidados en salud, en la atención primaria. En el marco de este artículo, al hacer un recorte de la referida disertación, nos ocupamos de la comprensión de lo que significa "ser travesti" para nuestras entrevistadas. Debido a la inmensa dificultad de identificar en la práctica las categorías diferenciadoras de las identidades de género, percibimos la necesidad de

${ }^{1}$ Psicóloga. Doutoranda em Psicologia pela Universidade Federal do Rio Grande do Norte (UFRN). Professora do Centro Universitário Facex - Natal/RN. E-mail: nathaliaduartem@ hotmail.com

${ }^{2}$ Graduada em Psicologia pela Universidade de Fortaleza, Mestre em Saúde Coletiva pela Universidade do Estado do Rio de Janeiro (UERJ), Doutora em Ciências Médicas pela Faculdade de Medicina da Universidade de São Paulo (USP). É Professora do Departamento de Psicologia da Universidade Federal do Rio Grande do Norte (UFRN), e está vinculada ao Programa de Pós-Graduação em Psicologia/PPGPsi. Coordena o Mestrado Profissional em Saúde da Família no Nordeste- MPSF/RENASF - núcleo UFRN. Coordena o LETHS - UFRN (Laboratório de Estudos em Tanatologia e Humanização das práticas em Saúde). E-mail: gsibele@gmail.com 
discutir el significado de ser travesti para las propias travestis. Utilizamos como instrumentos tecno-metodológicos la entrevista en profundidad y taller con uso de escenas. Para el análisis interpretativo de las narrativas recurrimos a la Hermenéutica-Dialéctica. A partir del diálogo con las narrativas llegamos a los siguientes resultados: El "ser travesti" como ser homosexual; ser femenina; no ser transexual; y aceptarse. Ante las diversas formas que las entrevistadas se definieron mientras travestis, vimos que no existe un proceso específico de construcción de sus identidades de género. Por último, se espera que la investigación pueda contribuir con el campo del conocimiento acerca del saber hacer en la asistencia a las personas travestis, dentro y fuera de la academia.

Palabras clave: travestis; transexualidad; homosexualidad; identidad de género; la hermenéutica.

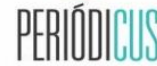

ISSN: 2358-0844

n. II, v. I mai. -out. 2019

p. 381-403. 
Uma última pergunta: O que é mais difícil? Ser um homem ou ser uma mulher? É duro ser homem, e é difícil ser mulher. Mas o mais difícil é tentar não esquecer quem de verdade queremos ser. (A LUTA..., 2005)

\section{Introdução}

As travestis pertencem a uma das possíveis identidades de gênero e, devido a busca de uma identidade que não lhes é a imposta culturalmente pela genitália que lhes acompanham, tornam-se uma parcela da população estigmatizada, que sofre preconceitos. As travestis têm alguns dos seus direitos fundamentais negligenciados e desrespeitados devido a estarem associadas a fatores estigmatizantes que as vulnerabilizam a adoecimentos e violências. Dentre os desviantes de um ideal heteronormativo, as travestis são as que mais sofrem agressões e discriminações.

Devido a estas constatações, foi desenvolvida uma dissertação que se propôs a dialogar sobre a vivência travesti na busca por saúde dentro do contexto da atenção primária em Natal. Porém, para a construção da referida dissertação, fez-se necessário compreender primeiramente quem era a pessoa travesti, como se definiria o "ser travesti", e como uma pesquisadora teria capacidade para delimitar este público. Esse trabalho se revelou bastante árduo e complexo, chegando à conclusão de que precisaria desenvolver um estudo sobre o que é ser travesti para as próprias pessoas travestis. Portanto, no âmbito deste artigo, nos debruçaremos sobre a compreensão do que significa "ser travesti” para as nossas entrevistadas.

\section{Percurso metodológico}

Para a realização deste estudo, o caminho teórico - metodológico escolhido foi a Hermenêutica Gadameriana aliada aos princípios dialéticos. É importante registrar que Gadamer (2002) se aproxima da dialética quando assegura que a compreensão só é possível pelo estranhamento, pois a necessidade de entendimento nasce do fracasso da transparência da linguagem e da própria incompletude e finitude humanas.

Os sujeitos desta pesquisa são travestis da cidade de Natal. O critério de inclusão dos participantes foi de ter buscado e/ou ter sido atendido em algum serviço de saúde da atenção básica dessa cidade. O local do acesso às narrativas das colaboradoras foi de acordo com a conveniência das entrevistadas, garantindo condições adequadas, a não interrupção e a privacidade. Algumas entrevistas foram realizadas nas casas das participantes e outras em seus locais de trabalho. Realizouse em diferentes bairros da cidade de Natal.

Periódicus, Salvador, n.11, v. 1, mai-out.2019 - Revista de estudos indisciplinares em gêneros e sexualidades Publicação periódica vinculada ao Núcleo de Pesquisa NuCuS, da Universidade Federal da Bahia - UFBA ISSN: 2358-0844 - Endereço: http://www.portalseer.ufba.br/index.php/revistaperiodicus 
Os contatos com os sujeitos da pesquisa foram feitos através dos encontros estaduais e nacionais de travestis, que ocorreram em Natal no ano de 2013, e também da Associação de Travestis Atrevida. Foram indicados, através da presidente da associação, alguns nomes para possível contato de entrevista, o que deu início ao método "bola de neve". A cada entrevistada era pedido o contato de outra travesti, e que pudesse ser falado o nome de quem tinha indicado o contato.

Utilizamos, para o acesso as narrativas das colaboradoras, a entrevista em profundidade com roteiro, e a oficina com o uso de "cenas". 3 Em termos de tratamento das entrevistas utilizamos o método de interpretação de sentidos, baseando-se em princípios hermenêuticos-dialéticos que buscam interpretar o contexto, as razões e as lógicas de falas, ações e inter-relações entre grupos e instituições. (GOMES e demais autores, 2005)

As participantes foram informadas da pesquisa no primeiro contato, no qual os objetivos do projeto foram esclarecidos a partir da apresentação do Termo de Compromisso Livre e Esclarecido, respeitando as regras éticas em conformidade com a Lei 466\2012. Garantimos um total de sete participantes, com idades que variaram de 28 a 52 anos. Em relação ao nível de escolaridade, duas possuíam ensino médio incompleto, duas ensino médio completo, duas superior incompleto e uma superior em andamento. As profissões que exerciam eram: cabeleireira, cantora, vendedora, manicure, profissional do sexo, cozinheira e militar reformada. Os nomes das entrevistadas foram alterados; utilizamos codinomes para evitar a identificação pelo perfil das mesmas. A pesquisa foi aprovada no comitê de ética da UFRN com parecer número 493.685.

\section{Entre o preconceito e a busca por respeito: apresentando as divas!}

Segundo Goffman (1988), o termo “estigma” fora criado pelos gregos, que se referiam a sinais corporais nos quais identificavam algo de extraordinário ou mau sobre o status moral do portador do estigma. Esses sinais eram feitos com cortes ou fogo no corpo para avisar que a pessoa era um escravo, um criminoso ou traidor, pessoa essa que devia ser evitada, principalmente em locais públicos. Atualmente, o termo é usado de forma semelhante ao original, porém, se refere muito mais a algo subjetivo do que a uma marca corporal.

3 As oficinas em grupo com utilização de "cenas" projetivas atendem ao intuito de aprofundamento dos dados da entrevista. Segundo Paiva (2005), o uso de cenas são ferramentas para conscientização, ação, invenção e circulação de repertórios discursivos - e não discursivos - de grupos e indivíduos, que podem resultar em mobilização individual e social para promoção da saúde.

Periódicus, Salvador, n.11, v. 1, mai-out.2019 - Revista de estudos indisciplinares em gêneros e sexualidades Publicação periódica vinculada ao Núcleo de Pesquisa NuCuS, da Universidade Federal da Bahia - UFBA ISSN: 2358-0844 - Endereço: http://www.portalseer.ufba.br/index.php/revistaperiodicus 
A sociedade categoriza as pessoas e define quais atributos são considerados comuns e naturais para os membros de cada uma dessas categorias. Então, quando um estranho nos é apresentado, procuramos aspectos que nos permitam prever a sua categoria juntamente com os seus atributos, a sua "identidade social". Tendo por base essas preconcepções, nós as transformamos em expectativas normativas, em exigências apresentadas de modo rigoroso. Então, um indivíduo que poderia ter sido facilmente recebido por nós em nossas atividades cotidianas é afastado por possuir um traço diferente das expectativas, destruindo a possibilidade de atenção para outras características suas. Ele possui um estigma, uma característica diferente da que havíamos previsto. (GOFFMAN, 1988)

Já os preconceitos são definidos como um conceito ou opinião formados antecipadamente, sem maior ponderação ou conhecimento dos fatos; julgamento ou opinião formada sem se levar em conta o fato que os conteste; superstição, crendice, suspeita, intolerância. Podemos dizer que os estigmas, mais abrangentes, se encontram na base dos preconceitos; estes, por sua vez, depois de instituídos socialmente e internalizados individualmente, passam a existir independentemente dos estigmas que possam tê-los originado. Os preconceitos podem gerar sentimentos negativos como ódio irracional ou aversão a outras raças, credos, religiões, como percebemos frequentemente em diversas relações sociais. Um exemplo conhecido é a aversão e, por vezes violência, dirigida às pessoas homossexuais (AGGLETON; PARKER, 2001), ou, no caso deste estudo, a pessoas travestis.

Atitudes oriundas do preconceito podem produzir comportamentos de discriminação, que isolam e segregam aqueles que carregam as marcas - os estigmas - de sua condição, excluindo-os, privando-os, tornando-os a parte do convívio social.

O momento inicial do encontro de algumas pessoas com uma travesti pode ser bastante perturbador, evocando fantasias arcaicas e atualizadas em torno das sexualidades, dos corpos e seus prazeres. A rigidez com que somos constituídos através de uma classificação estrita dos modos masculinos e femininos de ser diante das expressões impede-nos de termos tranquilidade frente as pessoas que apresentam um sexo genital masculino e uma identidade social de gênero feminina. As travestis embaralham os códigos de inteligibilidade dos gêneros levando os desavisados a uma situação de confusão mental e, quando associados ao moralismo religioso, torna-se disparador poderoso para o exercício da discriminação, exclusão e violência contra as travestis. (PERES, 2008)

Em um primeiro momento da entrevista, quando pedimos que elas falassem livremente sobre as suas vidas, já é possível identificarmos marcos intensos da relação de discriminação em suas vidas. 
Se dependesse de mim eu seria o contrário de mim, mas eu não consigo. [...] Minha mãe já tentou até me matar com gás. [...] Às vezes eu to mais em Natal aqui como um refúgio. [...] É triste pra mim, não é bom ser travesti, é horrivel. Mas pelo menos não é aquela coisa tão pequena lá. Lá eu já fui até apedrejada, e não foi por palavras, foi por pedras mesmo. (ANGELINA JOLIE)

Mesmo assim, depois que eu comecei a me soltar, eu conheci o peso do preconceito, o peso da transfobia que dói, dói, dói mesmo pra valer. [...] Muitas vezes até você tá de boca calada, mas não querem nem saber se você fala, querem saber que você é uma travesti, então vou te humilhar e é uma humilhação gratuita. (NAOMI CAMPBELL)

Nos discursos das entrevistadas, há um forte retrato de suas dores em função dos preconceitos e discriminações vivenciadas e o desejo de serem respeitadas e aceitas em suas diferenças. Da dor da rejeição familiar, a busca do anonimato em uma capital para protegerem-se e evitar a humilhação, até a luta cotidiana contra a morte social, são algumas das formas das travestis se apresentarem evidenciando as marcas da estigmatização que vivenciam. Elas passam, diariamente, por situações de desrespeito. Carrara e Ramos (2005), em uma pesquisa nas paradas gays do Rio de Janeiro, trazem índices que comprovam que as travestis são do grupo que mais sofrem discriminação e agressão devido aos estigmas que estas carregam.

Muller (2007) destaca quatro fatores para ser esse grupo tão estigmatizado: A determinação que as travestis apresentam em modificar o seu corpo, a personificação da ambiguidade entre masculino e feminino, a imaginada explicitação de sua condição sexual e por lhes restar, quase sempre o trabalho como profissionais do sexo.

Muitas travestis vêm morar na capital por não aguentarem o peso do preconceito em suas cidades do interior, existente também em uma capital, mas reduzido pelo anonimato. Como nos traz Pelúcio (2009, p.43): "Essa relação com a vida urbana remonta à trajetória de tantos homens efeminados que buscaram no anonimato das cidades um espaço para tornar suas vidas mais habitáveis”.

Devido a todas as discriminações sofridas, o respeito torna-se algo de extrema importância na vida de uma travesti, sendo altamente valorizado tal conquista:

Eu gostaria de falar da minha vivência enquanto travesti, que eu sempre fui muito bem respeitada, minha família graças a Deus sempre me apoiaram. (...) Acho que as pessoas 
começaram a me respeitar a partir do momento que eu comecei a lutar pela causa né. (GISELE BUNDCHEN)

Até agora to sendo feliz (sorriso). Tenho um parceiro, vivo há 16 anos com ele e... construí duas casas, tenho meu trabalho. [...] 'Mãe, olha, você não se preocupa que neto você nunca vai ter, vou viver minha vida, não sou de bagunça, vou respeitar pra ser respeitado', e até hoje to vivendo, 42 anos bem vividos. (BEYONCÉ)

Eles [familiares] saem comigo pra tudo que é canto, minha mãe vai pra umas festinhas e sai comigo normal. Porque se eu não respeitasse onde eu moro, não tivesse aquela dignidade, eles não iam sair comigo, não iam! (JULIA ROBERTS)

Na vida das nossas Divas, nem tudo são dores. A felicidade, o respeito e a dignidade também fazem parte da história de construção delas. A militância aparece na vida de Gisele como algo que lhe trouxe o respeito tão caro em suas vidas. Beyoncé ressalta a sua felicidade e tudo que conseguiu construir em seus 42 anos "bem vividos". E Julia enfatiza o respeito que conseguiu da sua família e da sua comunidade devido ao seu comportamento "digno". Apesar de todos os obstáculos enfrentados, elas encontram estratégias de sobrevivência para seguirem em frente no seu projeto de "ser quem eu sou".

Eu nasci nesta condição e não tem como modificar. Infelizmente não tem né? Apesar de que, eu falei infelizmente mas eu adoro ser o que eu sou (risos), eu me sinto feliz assim. Apesar de tudo e de todos, a gente se adapta, ser humano se adapta a tudo. Não moram na neve? (risos) A gente se adapta a tudo. (NAOMI CAMPBELL)

“Eu adoro ser o que eu sou”. E o que ela é? Pergunta difícil para qualquer um responder sobre si. O que é ser mulher? O que é ser homem? O que é ser travesti? A cada uma dessas perguntas caberia uma infinidade de respostas. Respostas que buscamos com as pessoas travestis e que só cabem a elas nos dar.

\section{Travestilidades: múltiplas, inúmeras, infinitas}

Quando se fala "as travestis", de maneira generalista, entende-se que falamos de travestilidades, pois existem múltiplas formas de ser e sentir-se travesti. Como nos trouxe Pelúcio (2009, p.27):

Periódicus, Salvador, n.11, v. 1, mai-out.2019 - Revista de estudos indisciplinares em gêneros e sexualidades Publicação periódica vinculada ao Núcleo de Pesquisa NuCuS, da Universidade Federal da Bahia - UFBA ISSN: 2358-0844 - Endereço: http://www.portalseer.ufba.br/index.php/revistaperiodicus 
Uso o termo no plural por entender que, cada vez mais, torna-se evidente que não há uma maneira única de constituir essa expressão de gênero. Como ocorre com outros segmentos sociais, as travestis têm se referenciado em imagens múltiplas do ser mulher/homem, em discussões cada vez mais presentes sobre o tema de gênero e sexualidade veiculadas em diversos meios de comunicação. Somem-se a isso, as variações regionais e de ambientes, as quais também incidem nessas escolhas.

Tagliamento (2012, p.12), em sua pesquisa, resolve utilizar o termo "mulher trans", pois era o termo usado pela população que ela estudou. Esse termo diz respeito tanto às travestis quanto às transexuais, mas não possui o mesmo sentido de "transgênero", entendendo esse como o trânsito entre um gênero e outro, enquanto que as mulheres trans não se consideram em transição, elas pertencem a um único gênero, o feminino. "A escolha por esse termo deve-se, também, ao fato de que muitas, no início da entrevista, diziam-se travestis, para, em seguida, dizerem que eram transexuais ou o inverso".

Entendendo a multiplicidade das identidades e as diferentes maneiras de defini-las, buscamos o significado de "ser travesti" para cada uma das nossas entrevistadas. Foram encontrados os seguintes sentidos: ser travesti é ser homossexual; ser travesti é ser feminina (mas não mulher); ser travesti é não ser transexual; ser travesti é aceitar-se.

Vamos ao diálogo com as categorias encontradas:

\section{5. "Ser travesti": é ser homossexual, ou mais que isso?}

A categoria de "sensibilidade sexual invertida", elaborada por Westphal em 1869, não diferenciava homossexualidade e transexualidade, e incluía as duas como inversão entre elementos masculinos e femininos da psicologia humana. Havelock Ellis, em 1899, e Richard von Krafft-Ebing, em 1931, consideravam a transexualidade como uma variante da homossexualidade, ou vice-versa. Magnus Hirschfeld em 1910 inventou os termos Transvestitismus (travestismo) e seelischer Transexualismus (transexualidade da alma) e pensou pela primeira vez o travestismo como um fenômeno distinto da homossexualidade. (BERNINI, 2011)

Leite Junior (2008) nos diz que um dos fatos importantes no livro de Hirschfeld - Transvestites: the erotic drive to cross-dress - é que ele vem trazer uma separação da concepção de "orientação sexual", do desejo de vestir roupas do sexo oposto. Uma coisa seria por quem a pessoa sente atração sexual, e outra, diferente, seria o prazer pelo uso de roupas do outro sexo. Portanto, as pessoas travestis poderiam ser heterossexuais, homossexuais, bissexuais ou qualquer outra das categorias existentes. 
Inclusive, a maioria dos casos expostos no livro são de homens que sentem prazer de vestir roupas femininas e sentem atração sexual apenas por mulheres. (LEITE JUNIOR, 2008)

Quase 40 anos depois, em 1949, David O. Cauldwell chamou seu ensaio de "Psychopathia trans-sexualis", mas apenas em 1953, no ensaio "Transvestitism and transexualism" de Harry Benjamin, o adjetivo "transexual" foi substantivado, passando a indicar uma identidade. Foi assim conceitualizada aquela diferença entre sexo, gênero e orientação sexual com a qual hoje medicina e psicologia pensam não apenas a homossexualidade e a transexualidade, mas também a heterossexualidade. (BERNINI, 2011)

Então, no meio científico, há mais de cinquenta anos, questões concernentes à orientação sexual são tratadas sob a perspectiva de que a sexualidade não está vinculada a uma lógica binária. Esta forma de encarar a sexualidade humana impôs novas reflexões acerca dos papéis sexuais na nossa sociedade. Ao se falar sobre sexualidade, é importante que se compreenda a existência e a diferenciação desses dois conceitos: orientação sexual e identidade de gênero. (CERQUEIRASANTOS e demais autores, 2010)

A expressão orientação sexual diz respeito especificamente ao sexo pelo qual o indivíduo se sente atraído sexual e emocionalmente. Já se falando em identidade de gênero, essa se relaciona com o gênero - masculino ou feminino - com o qual o indivíduo se identifica. Diversas combinações podem ocorrer entre orientação sexual e identidade de gênero de forma que podemos encontrar uma expressão social de sexualidade que não revela, a priori, a orientação sexual. No entanto, os estereótipos em torno das orientações sexuais são comuns e até socialmente reforçados na configuração heteronormativa da cultura judaico-cristã. (CERQUEIRA-SANTOS e demais autores, 2010)

Porém, nas falas de algumas entrevistadas podemos perceber a relação que elas fazem entre a orientação sexual homossexual e a identidade de gênero travesti, como se fossem sinônimos. Sobre este ponto é importante frisar que, ao analisarmos os discursos das entrevistadas, reconhecemos que as mesmas são partes constituintes e constituídas da nossa sociedade heteronormativa, onde normas definem verdades sobre os gêneros e sobre as sexualidades. Vejamos algumas falas que apontam para a similaridade entre os conceitos de gênero e sexualidade:

Adoro os travestis, aqueles esnobes que são bonitos, que são belos, sempre quer mostrar mais, eu acho interessante. Agora pra mim, eu não concordo muito não, eu acho que mesmo que você tenha sua tendência homossexual, você deve manter. Se fossem mais simples talvez o 
preconceito fosse menos. (MADONNA)

Não é nem que você não queira, por isso eu acho ridículo quando falam em opção sexual, eu nunca tive que optar por nada, porque se eu tivesse que escolher eu não teria escolhido, quem é que vai escolher nascer pra ser humilhado, massacrado, pisado o tempo todo, ser visto como chacota, ninguém vai escolher isso. Por isso opção não existe, é a condição sexual. Eu nasci nesta condição e não tem como modificar. (NAOMI CAMPBELL)

Outra relação estabelecida entre as entrevistadas e a homossexualidade é enxergar o "ser travesti" como um estágio mais avançado do "ser gay", reproduzindo uma concepção que vê as travestis como uma forma máxima da homossexualidade. Vejamos alguns recortes:

Também tenho um irmão que é gay, só que ele é gay normal, que a gente costuma dizer normal, só eu que sou travesti. (...) Quem tem silicone, a hormonizada pode ser bonita como for mas ela já não vai querer andar, porque pra elas a gente ainda não é travesti, a gente é gayzinho. (...) 'Julia, você não vai só ser isso aqui [gay afeminado], você vai virar travesti, aposto com você'. (JULIA ROBERTS)

Dos meus 14 até meus 18, 19, 20 anos, eu me considerava um homossexual. Hoje eu me considero uma travesti. (...) Não vai ser mulher nunca, tem que botar na cabeça. Sou uma travesti, ou sou um gay, ou sou um homossexual, independente de qualquer coisa. (BEYONCÉ)

Kulick (2008, p.230) apresenta uma crítica aos pesquisadores brasileiros pela forma como estes descrevem as travestis, sem escutá-las de fato: “Ao invés de escutarem o que elas dizem - e elas dizem explicitamente que são homossexuais - esses autores preferem formatar a imagem das travestis como ícones pós-modernos, sugerindo que elas rejeitam toda e qualquer identidade":

Benedetti (2005) vê essa ligação com a homossexualidade como uma diferença entre as transexuais americanas e as brasileiras. Para as americanas, o interesse erótico por homens não é um fator determinante na construção de sua identidade sexual, que está centrada em sua condição feminina, percebida como um atributo mental ou orgânico e desvinculada do desejo e da orientação sexual. Há transexuais que vivem e se concebem como heterossexuais. Já para as brasileiras, a questão de ser viado é onipresente em suas narrativas dos processos de transformação do gênero.

O ser homossexual como base para a transformação de gênero está presente nas falas já citadas 
de Beyoncé e Julia: “me considerava um homossexual. Hoje eu me considero uma travesti”, e "ele é gay normal, só eu que sou travesti”.

Kulick ainda nos diz que, para as travestis, um homem gay - e que gosta de ser penetrado -, disfarçam e fingem ser homens, quando não o são. Enquanto que as travestis consideram-se homossexuais mais honestos e mais radicais. "Elas se veem como a Arquiencarnação, a Verdadeira expressão, o ponto final e almejado do desejo homossexual. Acreditam ser o desejo homossexual em sua forma mais perfeita e acabada". (KULICK, 2008, p.235) Percebemos esse sentimento da verdade no "ser travesti" no seguinte recorte:

Assim, porque antigamente, antes de eu ser travesti eu andava muito aqui no centro, então eu achava bonito, eu achava interessante o modo delas, entendeu? O modo delas eu achava ali... não sei nem o que que passava, mas eu achava uma coisa, elas eram as verdadeiras, que queriam enfrentar a sociedade, tá entendendo? (JULIA ROBERTS)

A admiração da entrevistada pelas travestis veio antes mesmo de ela se identificar como tal, e se fundamenta no fato de ela vê as travestis como aquelas que não abdicam de ser do jeito que querem para se sujeitarem às normas sociais. Sendo assim reconhecidas como "as verdadeiras". Percebemos, nessa fala, a travestilidade não só como um estágio a mais do que o "ser gay", mas como um estágio melhor e mais evoluído, verdadeiro - para Júlia, são aquelas que não escondem a sua homossexualidade atrás de uma imagem masculina.

Pelúcio (2009) vem trazer que, em muitos casos, é ainda quando vivem com a família que as travestis, ainda "viadinhos", veem pela primeira vez outra travesti e se identificam com elas. Enxergam ali um lugar no mundo, um lugar que começa no corpo de outra travesti.

Já Damásio (2011), ele nos indica que o processo de construção da corporeidade feminina pelas travestis não é algo que remeta a um desenho final do feminino, não garante a lógica do "gayzinho-drag-travesti-transexual", não sendo as travestis observadas enquanto partes de um grupo coeso. A autora ainda diz que, para a compreensão desses sujeitos, é necessário enxergar a sua potencialidade de trânsito, de mobilidade, desmontando os lugares do feminino e do masculino, não se constituindo em um lugar de estaticidade. 


\title{
6. Ser travesti é ser feminina
}

A feminilidade buscada pelas travestis é construída de diferentes formas nas mais variadas sociedades. Um dos vários exemplos pesquisados por antropólogos das diferentes perspectivas de gênero nas sociedades é o de Margaret Mead, que, em seu livro Sexo e temperamento, estudou um grupo chamado “os tchambuli habitantes do lago". Nesse grupo, os homens dedicavam suas vidas à arte e aos cuidados de sua apresentação social, como ornamentos corporais e modos de comportamento. Enquanto entre as mulheres, a regra era o trabalho, o companheirismo e o maior desejo sexual, sendo elas as que tomavam as iniciativas nesta comunidade. A pesquisadora não considerou os homens afeminados ou as mulheres masculinizadas, apenas tinham "temperamentos" considerados invertidos para a nossa sociedade. (MEAD, 1969)

Sobre essas diferenças sexuais, Mead (1969, p.9) fala:

\begin{abstract}
Enquanto não conseguirmos entender cabalmente como uma sociedade pode moldar todos os homens e mulheres nascidos em seu âmbito de modo que se aproximem de um comportamento ideal inerente apenas a alguns poucos, ou restringir a um sexo um ideal de comportamento que outra cultura logrou limitar ao sexo oposto, não poderemos falar de forma muito compreensiva sobre diferenças sexuais.
\end{abstract}

Desde que Margaret Mead escreveu seus dois famosos livros: Sexo e Temperamento, 1935, e Macho e Fêmea, 1946 e especialmente desde o surgimento do feminismo moderno, a distinção entre sexo fisiológico e sexo social - papéis sociais - tem sido discutida cada vez mais. Segundo Fry e Mcrae (1986), a partir da constatação de que os papéis sexuais de - "homem" e "mulher" variam de cultura para cultura e de época para época, é agora um lugar-comum observar que cada sociedade, classe e região tem a mulher e o homem que merece. Ninguém hoje em dia acredita que as diferenças de comportamento entre os dois sexos possam ser explicadas apenas em termos de diferenças biológicas, pois reconhece-se que os papéis sexuais são forjados socialmente.

Porém, a busca pela compreensão dos gêneros, dos incômodos de ser um homem ou uma mulher "de verdade" não penetrou todos os lares. Não foi possível ainda desconstruir o que a cultura ocidental definiu como comportamento adequado aos gêneros nem entendê-los como uma construção social.

O cotidiano das crianças é permeado por comentários que definem o que é "coisa de menino" e "coisa de menina". Aqueles que nasceram com a genitália masculina precisam dar contas desses comportamentos e seguir o roteiro de características definidos a priori para serem homens. Quando 
vão crescendo as cobranças se tornam maiores. As brincadeiras se diferenciam, assim como as formas de contato com as meninas. Não poder transitar no mundo das mulheres faz parte do ritual de segregação. (SILVA, 2002) As falas a seguir retratam um pouco dessa realidade:

Porque as pessoas esperam que aquele corpinho que nasceu masculino seja masculino pro resto da vida. Mas não, quando dá um certo tempo da vida ele pá: 'não sou homem mamãe!'. Na minha cabeça eu não consigo pensar como um homem, por mais que eu me esforce eu não consigo. (NAOMI CAMPBELL)

Com 14 anos eu fui dizer a minha mãe, ai ela disse: 'Já sabia!', que eu não era um homem de verdade. (JULIA ROBERTS)

Segundo Silva (2002), o “tornar-se homem” sustenta-se através de negações. Ser homem é negar três vezes. Negar ser mulher, ser menino e ser homossexual. Como vimos nas falas acima, as entrevistadas não poderiam ser consideradas "homens de verdade" por quebrar essas negações, primeiro identificadas enquanto homossexuais, e depois indo em direção ao "ser mulher", feminilizando-se cada vez mais.

Dentro do contexto das possibilidades de performances de gênero, percebemos que as transformações do corpo a que as travestis se submetem variam singularmente, não havendo uma delimitação do quão aproximado do feminino precisa-se estar para serem consideradas como tal. Como nos trouxe Bento (2006, p.44): “O que faria um sujeito afirmar que pertence a outro gênero é um sentimento; para muitos transexuais, a transformação do corpo por meio de hormônios já é suficiente para lhes garantir um sentido de identidade".

Muitas falas apontam para a autoimagem das travestis como seres femininos, mas não como mulheres:

É o que me reconheço, me sentir feminina. Eu nunca disse pra ninguém que eu queria ser mulher, eu quero ser reconhecida como gênero feminino. (GISELE BUNDCHEN)

é, não que tenha um comportamento de mulher, que a gente nunca vai ser mulher, por mais que faça a cirurgia e tudo. Travesti é quem é mãe, tá entendendo? É você ter um comportamento digno, tem que chegar pelo menos próximo do comportamento de uma mulher. Ter sua vida normal, não se depravar. (JULIA ROBERTS) 
Eu me considero uma travesti. Porque? Não sou mulher, também não quero ser mulher. Quero que as pessoas me respeitem do jeito que eu sou. Eu posso vestir uma roupa de mulher, eu posso vestir uma calça, posso me maquiar, mulher nunca vou ser. (...) Eu sou uma travesti? Sou. Tenho peito, vivo com homem, me considero muito feliz. Vivo uma relação entre homem e mulher, porque eu faço tudo dentro de casa, aprendi a fazer tudo, graças a Deus. (BEYONCÉ)

Percebe-se também que o "ser travesti” está diretamente ligado ao que elas consideram "ser mulher", já que é necessário aproximar-se do comportamento de uma mulher para ser uma travesti. Alguns elementos foram destacados quando estas se referiam a um "comportamento de mulher": Ser mãe, ser digna, não se depravar, ser natural, se comportar, ser educada. Essas características estão extremamente ligadas a uma concepção social baseada no binarismo de gênero presente em nossa sociedade.

As entrevistadas afirmam a sua relação com a feminilidade, mas negam serem mulheres. Elas se remetem a uma concepção de mulher como sexo biológico e não como uma construção social, quando afirmam, por exemplo, que "a mulher nasce mulher", e que uma travesti, independente de tudo que ela faça, nunca será uma mulher.

Essas falas corroboram com os estudos de Beneditti (2005) quando ele diz que a maior parte das travestis não se iguala às mulheres, tampouco desejam fazê-lo. O feminino travesti não é o feminino das mulheres. É um feminino que não abdica de características masculinas, porque se constitui em um constante fluir entre esses polos, quase como se cada contexto ou situação propiciasse uma mistura específica dos ingredientes do gênero.

Segundo Pelúcio (2009, p.93):

As travestis sabem que não são mulheres, nem desejam sê-lo. São 'outra coisa', uma 'coisa' difícil de explicar porque, tendo nascido 'homens', desejam se parecer com mulheres, sem de fato ser uma, isto é, ter um útero e reproduzir. É assim que Junot, travesti veterana, me explica o que é ser mulher: 'não é ter uma vagina, não! É ter útero, é dar a vida. Tem uns viados doidos aí que dizem que são como mulheres. Eu pergunto logo: 'ah é?! Pariu quantos?!' Pariu no máximo um furúnculo. Que mulher, o quê?!' (...) Dessa forma, para ser mulher mesmo é preciso ter 'buceta/útero', compondo um sistema que faz da genitália e do aparelho reprodutor os definidores do que seria o verdadeiro gênero. As incorporações protéticas não as farão 'mulher', e sim 'femininas'.

Periódicus, Salvador, n.11, v. 1, mai-out.2019 - Revista de estudos indisciplinares em gêneros e sexualidades Publicação periódica vinculada ao Núcleo de Pesquisa NuCuS, da Universidade Federal da Bahia - UFBA ISSN: 2358-0844 - Endereço: http://www.portalseer.ufba.br/index.php/revistaperiodicus 
Já no final da fala, Beyoncé traz outra concepção de "ser mulher", quando afirma que "vivo uma relação entre homem e mulher, porque eu faço tudo dentro de casa". Nessa fala, Beyoncé já se coloca no papel de mulher, e se sente assim porque faz atividades domésticas, sendo, portanto, o papel desempenhado que torna alguém homem ou mulher.

Assim, como nos trouxe Damásio (2011, p.230) o "ato de constituir-se enquanto travesti traria tanto um sentido habilitador, quanto violador da palavra sujeição, deslizando ora para a adequação das normas de gênero, ora para a subversão das mesmas”.

Preciado (2008) vem chamar "programação de gênero" a uma tecnologia psicopolítica de modelização da subjetividade que permite produzir sujeitos que se pensam e atuam como corpos individuais, que se autocompreendem como espaços e propriedades privadas, com uma identidade de gênero e uma sexualidade fixas. A programação de gênero dominante parte da seguinte premissa: um indivíduo $=u m$ corpo $=u m$ sexo $=$ um gênero $=$ uma sexualidade. Desmontar essas programações de gênero, processo de desconstrução que poderia assemelhar-se ao que Judith Butler chamou de “desfazendo gênero", implica em um conjunto de operações de desnaturalização e desidentificação.

Segundo Leite Junior (2008), um exemplo da não inteligibilidade de vivências que fogem a esta coerência hetero-cis-normativa é a pessoa que, ao comentar sobre uma mulher transexual lésbica, afirma não entender porque "uma pessoa que é homem, faz uma cirurgia para se tornar mulher, se deseja se relacionar sexualmente com outras mulheres!”.

Enfim, o travestismo (cross-dressing), sobretudo quando se apresenta como paródia drag, no parecer de Butler, desestabiliza as distinções entre natural e artificial, entre interior e exterior, demonstrando que o gênero - todo gênero - não é um status, mas um fazer, apesar de ser um fazer por parte de um sujeito que pode ser definido como existente antes da ação. Para Butler, o travestismoé uma "experiência subversiva" muito importante. Ela entende que essa experiência não revela nenhuma verdade profunda do sexo e da natureza humana, mas mostra a estrutura superficial de toda identidade sexual. O travestismo é uma prática transformadora não pelo fato de anunciar um futuro no qual vencerá a confusão dos gêneros, mas por permitir compreender criticamente um presente no qual somos todos e todas - desde sempre e necessariamente - travestis. (BERNINI, 2011, p.14-16)

\section{Ser travesti é não ser transexual}

Peres (2008) conceitua, diferentemente das travestis, as transexuais, que, segundo ele, são pessoas que não se identificam com seus genitais biológicos - e suas atribuições socioculturais -, e

Periódicus, Salvador, n.11, v. 1, mai-out.2019 - Revista de estudos indisciplinares em gêneros e sexualidades Publicação periódica vinculada ao Núcleo de Pesquisa NuCuS, da Universidade Federal da Bahia - UFBA ISSN: 2358-0844 - Endereço: http://www.portalseer.ufba.br/index.php/revistaperiodicus 
podem, por meio da cirurgia de transgenitalização, construir suas expressões de gênero em consonância com seu bem-estar biopsicossocial e político. Já os transgêneros são pessoas que temporariamente se caracterizam com o sexo oposto, na maioria das vezes com finalidades artísticas, lúdicas ou eróticas. Entre eles encontramos transformistas, drag queens, drag kings, crossdressers e outros(as).

Já Bernini (2011), ele traz uma definição semelhante à de Peres em relação às pessoas transexuais, porém, fala de forma diferente em relação ao que ele chamou de transgender. Para ele, transexual é quem faz uma trajetória voltada para modificar os próprios caracteres físicos e os próprios genitais, tornando-se o mais possível semelhante às pessoas do sexo oposto, e transgender é, pelo contrário, quem escolhe uma identidade intermediária entre um gênero e o outro, colocando-se num continuum que reconhece como pontos extremos os dois gêneros definidos pelo sistema binário.

Em uma perspectiva transgender, a sexualidade não representa uma alternativa rígida entre o masculino e o feminino, mas se configura como uma progressão entre o masculino e o feminino rica de nuances. Ao longo desse continuum, todo ser humano deveria ter o direito de decidir onde colocar o próprio corpo, plasmando para a própria identidade a forma da qual poderá tomar o maior prazer. (BERNINI, 2011)

Vejamos o que disse nossa colaboradora:

Ser travesti é apenas a pessoa que se traveste. Não quer dizer o gênero dela, porque os travestis são ativos e passivos. E a transexual não. Algumas pessoas pensam que a transexual é a pessoa que faz a cirurgia de readequação, mas não é, ao meu ver não é. A transexual é aquela que se sente totalmente mulher. [...] A travesti pode ser ativa e passiva, não se denomina praticamente uma mulher. (ANGELINA JOLIE)

Alguns discursos apontaram as transexuais como aquelas com o desejo de realizar a cirurgia de readequação sexual, e as travestis como as que se sentiriam à vontade com seu órgão genital, podendo até chegar a fazer uso dele, sendo ativas nas relações sexuais. Esses relatos corroboram com os achados de Benedetti, quando este relata uma discussão no grupo de travestis do qual participava: "Sobre as semelhanças e diferenças entre travestis e transexuais, chegou-se à conclusão que o principal traço diferenciador é que as últimas não aceitam suas genitálias e negam ter nascido homens, enquanto as travestis fazem uso ativo de seus órgãos sexuais”. (BENEDETTI, 2005, p.113)

Kulick (2008) afirma que muitas travestis se sentem livres para alterar diversas partes do 
corpo, mas o órgão sexual não pode ser alterado. Como ilustra a fala da entrevistada:

Às vezes eu fico brincando com as meninas, elas dizem: 'tu vai ficar mais louca do que já é'. Não penso em fazer não [cirurgia de readequação sexual], é uma mutilação, já basta as coisas que a gente faz, e levar mais esse pecado, tirar um negócio que você já nasceu com ele. (JULIA ROBERTS)

A ideia de que elas vão ficar loucas se fizerem a cirurgia de transgenitalização é um lugar comum no imaginário de muitas travestis, reafirmado aqui no discurso de Julia. A perda do pênis e do gozo masculino se tornaria insustentável com o passar do tempo para aquelas que não fossem "transexuais de verdade". E só quem deteria o conhecimento para saber identificar um transexual verdadeiro $^{4}$ seria a ciência biomédica.

O saber médico, ao dizer "transexual”, está citando uma concepção muito específica do que seja um/a transexual. Esse saber médico apaga a legitimidade da pluralidade, uma vez que põe em funcionamento um conjunto de regras consubstanciado nos protocolos, que visa a encontrar o/a "verdadeiro/a transexual". O ato de nomear o sujeito de transexual implica pressuposições e posições sobre os atos apropriados e os não apropriados que os/as transexuais devem atualizar em suas práticas. (BENTO, 2006, p.47)

Nota-se que o que define o diagnóstico de "transexualismo" é uma concepção normativa dos sistemas de sexo-gênero, fundamentados numa matriz binária heterossexual que se converte em sistema regulador da sexualidade e das subjetividades. (ARÁN; MURTA; LIONÇO, 2009)

Se uma "mulher de verdade é discreta na forma de maquiar-se, nos modelos das roupas, se fala baixo e gesticula comedidamente e tem uma voz que não lembra os falsetes das travestis”, então, há todo um conjunto de tecnologias que são utilizadas para construir um sujeito transexual que não tenha em suas performances de gênero nenhum sinal que os identifique como tal. "A coerência dos gêneros está na ausência de ambiguidades”. (BENTO, 2006, p.18)

Eu me considero travesti, embora eu tenha comportamento de transexual, mas... sou travesti. Eu adoro a minha casa, adoro ficar na minha casa, sou muito caseira, adoro meu cachorro,

4 A transexualidade foi incluída no DSM III (Manual Diagnóstico e Estatístico das Desordens Mentais) em 1980, e hoje é nomeada como Transtorno de Identidade de Gênero (TIG).

Periódicus, Salvador, n.11, v. 1, mai-out.2019 - Revista de estudos indisciplinares em gêneros e sexualidades Publicação periódica vinculada ao Núcleo de Pesquisa NuCuS, da Universidade Federal da Bahia - UFBA ISSN: 2358-0844 - Endereço: http://www.portalseer.ufba.br/index.php/revistaperiodicus 
adoro minha sobrinha, sabe? Então, nesse ponto eu me sinto um pouco transexual. [...] Já o lado travesti é... é... que eu me sinto bem com meu sexo, entendeu? Não tenho pretensão nenhuma de fazer cirurgia. Embora eu não pratique o lado ati... ativo, mas... eu tenho essa ambiguidade, de reconhecer essas duas facetas. [...] As pessoas acham que uma transexual ela tem que ser feminina, pacata, não falar alto, tem que ser toda delicadinha. 'Ai, aquela ali é travesti, porque ela tem cara de homem, tem comportamento de travesti' mas não, aquela ali é uma transexual, a fisionomia dela não define a transexualidade. [...] Porque não existe uma regra né? Você não é mulher, porque você é mulher feminina. (GISELE BUNDCHEN)

Gisele afirma se considerar travesti, embora diga que tem comportamento de transexual, e quando questionada sobre como seria esse comportamento de transexual, ela apresenta um discurso pautado nas normas de gênero convencionais. Em seguida, Gisele muda o seu discurso, reproduzindo agora uma fala mais politizada, em que ela afirma que a diferença entre travestilidade e transexualidade só pode ser dada por cada pessoa, sendo mais um sentimento do que um conjunto de regras.

Nesse sentido, não existe um processo específico de construção das identidades de gênero nas transexuais. Não se deve esperar de transexuais um comportamento fixo, rígido, adequado às normas de feminilidade ou de masculinidade. (ARÁN; MURTA; LIONÇO, 2009)

Como nos trouxe Beneditti (2005), ainda que muitas travestis tenham o desejo de saber mais sobre as diferenças entre o seu corpo e sua identidade e entre elas e as transexuais, poucos são os traços diferenciadores que fazem sentido em seu universo. Muitas ficam tentando entender se são ou não transexuais, outras afirmam inconteste sua transexualidade, e há aquelas que acham desnecessário esse debate, como Gisele:

Eu não quero ser rotulada como travesti nem como transexual, quem tem rótulo é coca-cola, eu não sou coca-cola, eu gosto de ser, eu gosto de me sentir cidadã, independente do meu gênero, independente do meu sexo, eu gosto de ser cidadã. (GISELE BUNDCHEN)

\section{Ser travesti é aceitar-se}

A ideia de corpo abjeto, que passamos a usar a partir de Butler (2002), inicialmente nos remetia às pessoas à margem social, sem assistência e credibilidade civil, pessoas que, de alguma forma, tiveram suas vidas impossibilitadas de reconhecimento e que se juntaram a tantas outras denominadas como “morte civil”. Mas a mesma Butler avançará nas análises sobre o assunto e proporá uma reversão 
analítica em que os corpos abjetos passam a serem problematizados como agentes de resistência e de enfrentamento ao biopoder. De um corpo despotencializado e fraco surge um corpo empoderado e forte, guerreiro e reivindicador de direitos, que passa a participar das esferas de poder e descobre nas ações do coletivo a possibilidade de ser respeitada e tratada como cidadã. Seu enfrentamento à heteronormatividade desestabiliza e coloca em questão a ordem normativa e disciplinar que é imposta pelo sistema sexo/gênero/desejo/ práticas sexuais. (PERES; TOLEDO, 2011)

Podemos ver um pouco dessa potência em alguns discursos. Vejamos alguns deles:

É enfrentar a vida como ela é. [...] Eu vestida de mulher, eu com minha personalidade, eu quero que a sociedade me aceite desse jeito. Ser travesti é isso: ter sua dignidade. Não é porque você é travesti que você vai se banalizar não. Ser digna de levar aquele nome: travesti! (JULIA ROBERTS)

Saber quem você é realmente, se identificar. Porque eu acho que quando você se identifica você já tem meio mundo andado pra um progresso seu mesmo, então eu acho que se aceitar e se identificar é um primeiro passo. (NAOMI CAMPBELL)

Nesses discursos, o "ser travesti” não passa mais por uma questão de gênero ou sexualidade, mas sim, como um autoconhecimento e um orgulho de ser travesti que levam a um enfrentamento do preconceito e a uma reinvindicação do direito de "ser quem eu sou".

Muitas travestis afirmam ser mulheres - principalmente as mais politizadas por um discurso que concebe gênero como uma construção social -, e muitas travestis se relacionam sexual e/ou afetivamente com outras mulheres - mulheres trans e/ou mulheres cis. ${ }^{5}$ Como relatou uma das participantes em um encontro de travestis que frequentei: "Elas podem até se enganar com alguns homens, mas amor verdadeiro mesmo só entre duas travestis", se referindo a alguns casais de travestis como o único fruto de um verdadeiro amor, já que os relacionamentos com homens - na experiência da entrevistada - são muitas vezes guiados por interesses financeiros destes para com elas. Uma definição estática e rígida do que é ser travesti se torna, pois, inviável, depois de conhecermos as particularidades desse universo.

5 Cis é a abreviação de cisgênero, que são pessoas que foram designadas com um gênero ao nascer e se identificam com ele, ou seja, pessoas não transgêneras.

Periódicus, Salvador, n.11, v. 1, mai-out.2019 - Revista de estudos indisciplinares em gêneros e sexualidades Publicação periódica vinculada ao Núcleo de Pesquisa NuCuS, da Universidade Federal da Bahia - UFBA ISSN: 2358-0844 - Endereço: http://www.portalseer.ufba.br/index.php/revistaperiodicus 
O convívio com as travestis faz com que essas concepções de múltiplas identidades tomem vida e estabeleçam-se sem deixar dúvidas da sua existência. Ao escutar narrativas tão diferentes para o que seria a mesma identidade, percebe-se que a singularidade está presente, e muitas vezes se sobrepondo a qualquer conceito de identidade rígida. A Madonna que nunca havia usado tecnologias artificiais para modelar seu corpo para o feminino, a Angelina que acredita perder a sua feminilidade quando para de tomar hormônios, a Gisele que não gosta de ser ativa nas relações sexuais, a Julia que adora usar o seu pênis e o tem como fonte de maior prazer, a Naomi que ainda se disfarça de "menino" para sair para algumas atividades do dia a dia a fim de não ser desrespeitada. Enfim, esses são só poucos exemplos das inúmeras possibilidades que muitos tentam enquadrar no termo "travestis". Corroboramos com Pelúcio, quando esta diz: "Quando falo em travestis, a sensação de simplificar um universo tão diverso me incomoda" $(2009$, p.42).

Para Bento (2012, p. 2663):

\begin{abstract}
Não existe uma 'identidade trans', mas posições de identidade organizadas através de uma complexa rede de identificações que se efetiva mediante movimentos de negação e afirmação aos modelos disponibilizados socialmente para se definir o que seja um/a homem/mulher de 'verdade'. Não há identidade sexual típico para as pessoas trans. Suas sexualidades são feitas do mesmo material que as outras experiências: interdição, desejo, rebeldia, sofrimento, alegria.
\end{abstract}

Diferentes definições existem sobre o que é ser travesti, como elas se identificam, qual a sua orientação sexual. Tendo cada vez mais a acreditar que não existem características definidas para essa identidade. Cada travesti é, sente e se relaciona de uma maneira própria, única. E entendendo a não viabilidade de uma classificação rígida para as identidades de gênero, neste trabalho nos referimos às pessoas que se reconheceram como travestis, independentemente de quais transformações estas tenham se apropriado em direção ao feminino.

[Ser travesti] É uma busca constante do eu. Acho que é isso. Do eu que tá dentro gritando: [em tom risonho] 'Eu sou mulher! Eu sou mulher! Eu sou mulher!', e a sociedade: 'Você não é! (E dá na cara) Você não é! Você não é! Nunca vai ser!', e você fica dentro: 'Ai eu sou, eu sou linda!' você fecha o olho e se imagina assim... uma Naomi Campbell, uma Gisele Bundchen. Eu sou mulher e pronto! Não importa o que os outros digam, entendeu? O que importa é o que você tá se achando por dentro, estando feliz por dentro. (NAOMI CAMPBELL) 


\section{Concluindo...}

O preconceito e a vulnerabilidade enfrentados pelas travestis são marcas muito fortes em suas vidas. Elas passam diariamente por situações de desrespeito, tendo os seus direitos negligenciados e encontrando vivências de dor e sofrimento, como ilustra a fala de Angelina: "Se dependesse de mim eu seria o contrário de mim”. Ser o contrário de si para amenizar a dor do desrespeito. Ser o contrário de si para se enquadrar em um modelo binarista e hetero-cis-normativo a que fomos ensinados a seguir e a excluir todos aqueles que não o seguem.

A rigidez com que somos constituídos através de uma classificação estrita dos modos masculinos e femininos de ser diante das expressões impede-nos de termos tranquilidade frente às pessoas que apresentam um sexo genital masculino e uma identidade social de gênero feminina.

O que é ser mulher? O que é ser homem? O que é ser travesti? Foram perguntas feitas no decorrer deste trabalho, e que tiveram várias respostas, mas, ao mesmo tempo, nenhuma. Porque não existe uma única resposta. Existem mil formas de ser e se sentir homem, mulher, cis ou trans.

Sendo assim, quando falamos "as travestis", de maneira generalista, entende-se que falamos de travestilidades, reconhecendo a existência de múltiplas formas de ser e sentir-se travesti. Entendendo essa multiplicidade, buscamos o significado de "ser travesti” para cada uma das nossas entrevistadas.

Os estereótipos em torno das identidades de gênero e das orientações sexuais são comuns e até socialmente reforçados na configuração da cultura judaico-cristã. Pode-se perceber a relação que as travestis fazem entre a orientação sexual homossexual e a identidade de gênero travesti, como se fossem sinônimos. Afirmaram também a sua relação com a feminilidade, mas negaram ser mulheres. Elas se remetem a uma concepção de mulher como sexo biológico e não como uma construção social. E, ainda, O "ser travesti" como um autoconhecimento, autoaceitação e um orgulho de "ser quem eu sou". De um corpo despotencializado e fraco pode surgir um corpo empoderado e forte, guerreiro e reivindicador de direitos.

Diante das diversas formas de se definirem enquanto travestis, vimos que não existe um processo específico de construção das suas identidades de gênero. Uma definição estática e rígida do que é ser travesti se tornou, pois, inviável, depois de conhecermos as particularidades desse universo. Cada travesti é, sente e se relaciona de uma maneira própria, e única. 


\section{Referências}

AGGLETON, P.; PARKER, R. Estigma, Discriminação e AIDS. Rio de Janeiro: Associação Brasileira Interdiciplinar de AIDS, 2001. (Coleção Cidadania e Direitos).

A LUTA pela beleza. Direção: Ekachai Uekrongtham. Bangkok: GMM Pictures Co, 2003. (118 $\mathrm{min})$, son., color.

ARÁN, M.; MURTA, D.; LIONÇO, T. Transexualidade e saúde pública no Brasil. Ciência e Saúde Coletiva, Rio de Janeiro, v. 14, n. 4, p. 1141-1149, 2009.

BENEDETTI, M. R. Toda feita: o corpo e o gênero das travestis. Rio de Janeiro: Garamond, 2005.

BENTO, B. A reinvenção do corpo: sexualidade e gênero na experiência transexual. Rio de Janeiro: Garamond, 2006.

BENTO, B. Sexualidade e experiências trans: do hospital à alcova. Ciência \& Saúde Coletiva, Rio de Janeiro, v. 17, n. 10, p. 2655-2664, 2012.

BERNINI, L. Macho e fêmea Deus os criou!? a sabotagem transmodernista do sistema binário sexual. Bagoas, Natal, v. 5, n. 6, p.15-47, 2011.

BUTLER, J. Cuerpos que Importam: sobre los limites materiales y discursivos del sexo. Buenos Aires: Paidós, 2002.

CARRARA, S.; RAMOS, S. Politica, direitos, violência e homossexualidade: pesquisa da $9^{a}$ Parada do Orgulho LGBT - Rio, 2004. Rio de Janeiro: Centro de Estudos e Pesquisa em Saúde Coletiva, 2005.

CERQUEIRA-SANTOS, E.; CALVETTI, P.; ROCHA, K. et al. Percepção de Usuários Gays, Lésbicas, Bissexuais e Transgêneros, Transexuais e Travestis do Sistema Único de Saúde. Revista Interamericana de psicología/Interamerican Journal of Psychology, Porto Alegre, v. 44, n. 2, p.235-245, 2010.

DAMÁSIO, A. C. Botando corpo e (re)fazendo gêneros. Bagoas, Natal, v. 6, p.211-241, 2011.

FRY, P.; MACRAE, E. O que é homossexualidade. São Paulo: Brasiliense, 1986.

GADAMER, H. G. Verdade e Método II. Petrópolis: Vozes, 2002.

GOFFMAN, E. Estigma: notas sobre a manipulação da identidade deteriorada. 4. ed. Rio de Janeiro: LTC, 1988.

GOMES, R.; SOUZA, E. R.; SOUZA, M. C. et al. Organização, processamento, análise e interpretação de dados: o desafio da triangulação. In: MINAYO, M. C. S. Avaliação por triangulação de métodos: abordagem de programas sociais. Rio de Janeiro: Fundação Oswaldo Cruz, 2005.

KULICK, D. Travesti: prostituição, sexo, gênero e cultura no Brasil. Rio de Janeiro: Fundação Oswaldo Cruz, 2008.

LEITE JUNIOR, J. “Nossos corpos também mudam”: sexo, gênero e a invenção das categorias "travesti" e "transexual" no discurso científico. 2008. Tese (Doutorado em Ciências Sociais)Programa de Pós Graduação em Estudos Sociais, Pontifícia Universidade Católica de São Paulo, São Paulo, 2008.

MEAD, M. Sexo e Temperamento. São Paulo: Perspectiva, 1969.

MULLER, M. I. Os médicos nunca me tocaram um dedo! Eu cansei daquele posto!: a percepção das travestis quanto ao atendimento em saúde. 2007. Trabalho de Concluisão de Curso (Especialização em Saúde Pública)- Faculdade de Medicina, Universidade Federal do Rio Grande do Sul, Porto Alegre, 2007.

PAIVA, V. Analysing sexual esperiences through scenes: a framework for sexualty education and evaluation. Sex education, London, v. 5, n. 4, p. 345-358, 2005.

PELÚCIO, L. Abjeção e Desejo: uma etnografia travesti sobre o modelo preventivo de AIDS. São Paulo: Annablume: FAPESP, 2009. 
PERES, W. S. Travestis: corpo, cuidado de si e cidadania. In: Seminário Internacional Fazendo Gênero 8: Corpo, Violência e Poder, 8., 2008, Florianópolis. Anais: [...]. Florianópolis: Editora Mulheres, 2008. p. 1-7.

PERES, W. S.; TOLEDO, L. G. Dissidências existenciais de gênero: resistências e enfrentamentos ao biopoder. Psicologia Politica, São Paulo, v.11, n. 22, p. 261-277, 2011.

PRECIADO, B. Testo Yonqui. Madri: España, 2008.

SILVA, G. S. N. AIDS: O adversário que nos reaglutina. In: SANTOS, T. F. (org.). Saúde Sexual e Reprodutiva: uma abordagem multidisciplinar. Recife: Editora Massangana, 2002.

TAGLIAMENTO, G. (In)visibilidades caleidoscópicas: a perspectiva das mulheres trans sobre o seu acesso à saúde integral. 2012. Tese (Doutorado em Psicologia)- Instituto de Psicologia, Universidade de São Paulo, São Paulo, 2012. 